\title{
Os Impactos do Programa Municípios Verdes (PMV) no Con- trole do Desmatamento da Amazônia: uma análise usando propensity score matching
}

\author{
Peterson Felipe Arias Santos* \\ Alexandre Nunes de Almeida** \\ Luciana Pacheco Trindade Lacerda*** \\ Samara Martins Silva**** \\ Ricardo Alves de Brito****
}

\begin{abstract}
Resumo: Este trabalho teve por objetivo quantificar e analisar os impactos do programa do estado do Pará "Municípios Verdes" (PMV) entre 2010 e 2013 através dos métodos de diferença nas diferenças e propensiy score matching. Os resultados sugerem que nem todos os participantes têm conseguido reduzir seus níveis de desmatamento em relação aos não participantes. No entanto, uma parcela dos municípios participantes, que já possuíam taxas reduzidas de desmatamento antes do início do programa em 2011, têm obtido sucesso em sustentar baixos níveis de desmatamento, e, portanto, seriam merecedores das vantagens jurídicas e econômicas oferecidas pelo PMV.
\end{abstract}

Palavras-Chaves: Desmatamento. Municípios Verdes. Avaliação de Impacto.

Classificação JEL: C21, Q28, Q23.

The Impacts of Green Municipalities Program (PMV) on Deforestation Control in Amazon: an analysis using propensity score matching

Abstract: This study aims to analyze the impacts of the Pará State's "Green Municipalities Program” (PMV) between 2010 and 2013 using difference-in-differences and

\footnotetext{
Mestre e Doutorando em Economia Aplicada pela ESALQ/USP. E-mail: peterson.arias@usp.br

* Professor Doutor do Departamento de Economia, Administração e Sociologia da ESALQ/USP. E-mail: alex.almeida859@gmail.com.

*: Mestranda em Economia Aplicada pela ESALQ/USP e Assistente de Pesquisa II na DIMAC/ IPEA.E-mail: lucianaptlacerda@gmail.com.

**: Bacharela em Gestão Ambiental pela UnB e Mestra em Recursos Florestais pela ESALQ/USP. E-mail:samara.martins@usp.br

Mestre em Economia pela UFPE e Doutorando em Economia Aplicada pela ESALQ/USP. E-mail: ricardo.alves.brito@gmail.com
} 
Santos; Almeida; Lacerda; Silva; Brito - Os impactos do Programa Municípios ...

\begin{abstract}
propensity score matching approaches. The results showed that participants have not been effective in reducing deforestation comparing to non-participants. However, a part of PMV participants, which had lower rates of deforestation before the beginning of the program in 2011, has been able to sustain deforestation rates at low levels, and, therefore they should be able to earn all the juridical and economic benefits that the PVM has to offer.
\end{abstract}

Keywords: Deforestation. Green Municipalities. Impact Evaluation.

JEL Classification: C21, Q28, Q23.

\title{
1 Introdução
}

O presente trabalho tem por objetivo quantificar e analisar a evolução do desmatamento, entre 2010 e 2013, nos municípios brasileiros que compõe a Amazônia Legal e que participaram do programa estadual paraense para redução do desmatamento Programa Municípios Verdes (PMV) e compará-los a seus pares - municípios com características similares - que não participaram. Para mensurar esse impacto, utilizou-se a metodologia de avaliação do tratamento sobre os tratados (average treatment effect on the treated) a partir das técnicas de emparelhamento por escore de propensão (propensity score matching - PSM) e diferença nas diferenças (DD).

A hipótese que norteia este trabalho é que os incentivos e vantagens oferecidos pela participação no programa como, por exemplo, maior segurança jurídica, acesso ao crédito e incentivos fiscais, contribuam para que as cidades envolvidas se esforcem em manter baixos níveis de desmatamento. Especificamente, tais vantagens podem se dar, no caso da maior segurança jurídica, por exemplo, pelo fim de embargos econômicos, enquanto a facilitação da obtenção de crédito ocorre pela habilitação da tomada de recursos por parte de posseiros nos municípios que atendam exigências do PMV, exigindo-se apenas que os produtores tenham um protocolo do pedido de regularização fundiária (BRASIL, 2012). No caso dos incentivos fiscais, estes ocorrem sob a forma da política do Imposto sobre Circulação de Mercadorias e Serviços (ICMS) Verde ${ }^{1}$ (PEREIRA et al., 2014) adotado também em outros estados brasileiros. Vale salientar, contudo, que tais benefícios não impõem que os munícipios sejam membros do PMV, mas sim que cumpram metas associadas a ele.

1 O chamado ICMS Verde - ou Ecológico - corresponde ao montante do ICMS total repassado pelos estados aos municípios por meio de critérios ambientais. A possibilidade de adoção destes critérios é prevista constitucionalmente, uma vez que os estados podem estabelecer regras próprias para alocação de $1 / 4$ da parcela destinada aos municípios, de modo que diversas unidades federativas já possuem esta política (THE NATURE CONSERVANCE, 2016). No caso do Pará, os critérios incluem: Cadastro Ambiental Rural (CAR), redução do desmatamento e percentual de Áreas Protegidas e Especiais nos territórios municipais (PEREIRA et al., 2014). 
Dessa forma, a participação no programa configura-se mormente um compromisso formal com a redução do desmatamento que, por sua vez, acarretará nos benefícios supracitados.

Segundo o site oficial do $\mathrm{PMV}^{2}$, atualmente 107 municípios paraenses participam do programa, entretanto este trabalho considera a lista de 92 cidades que haviam assinado o Termo de Ajustamento de Conduta (TAC) com o Ministério Público Federal (MPF), ou seja, que participavam do programa, e que são apresentadas no relatório oficial do programa referente ao período entre março de 2011 e dezembro de 2012. Este TAC representa o compromisso formal do município com metas associadas à redução do desmatamento, esquemas de monitoramento, Cadastro Ambiental Rural (CAR) e educação ambiental, uma vez que não há requisitos para a entrada no PMV - aspecto relevante à análise posterior. Neste sentido, o cenário base deste trabalho avalia o impacto do programa sobre o desmatamento entre 2010 e 2013 em todos os 92 municípios signatários de TACs com o MPF relativamente a municípios similares, mas não participantes do programa. Alternativamente, estabeleceu-se, ainda, um cenário em que o impacto é avaliado em um subconjunto de 47 participantes com melhores indicadores ambientais no início do programa.

O debate nacional e internacional sobre a economia do desmatamento iniciou-se na década de 1970 e abrange amplo espectro de áreas do conhecimento, estando além do escopo desse trabalho. No entanto, entre as principais causas apontadas para o desmatamento nas florestas tropicais, o uso extensivo da agropecuária, direitos de propriedade mal definidos, comércio internacional, construção de estradas e crescimento populacional, estão entre as mais estudadas (REIS; GUZMAN, 1992; PFAFF, 1999; WALKER; MORAN; ANSELIN, 2000; WEINHOLD; REIS, 2001; ANDERSEN et al., 2002; MERTENS et al., 2002; MARGULIS, 2004; CHOMITZ; THOMAS, 2003; PFAFF et al., 2007; DINIZ et al., 2009; ARAUJO et al., 2009; RIVERO et al., 2009; BARONA et al., 2010; FARIA; ALMEIDA, 2016).

Particularmente no caso da região Amazônica, parece não ter se formado um consenso sobre quais seriam os determinantes que mais contribuem para desmatamento. Kaimowitz et al. (2004), Brandão, Rezende e Marques (2005) e Fearnside (2006) apontam que o desenvolvimento dessa região, somado ao aumento das atividades produtivas contribuíram, mesmo que indiretamente, para o agravamento do desmatamento. Além disso, fatores como avanço da pecuária na fronteira agrícola para atender a demanda externa, conflitos de terras entre fazendeiros, posseiros e povos indígenas, e aumento populacional mostram-se significativamente mais relevantes. Por outro lado, Prates e Silva (2007) afirmam que algumas variáveis podem ser consideradas para explicar o desmatamento em alguns estados, mas em outros não, como, por exemplo, o efeito da malha viária existente (melhoria da infraestrutura), que explicaria $0,06 \%$ do desmatamento no Acre e 8,30\% no Pará. A acessibilidade, associada à malha viária, também foi apontada como fator relevante, mas

$2<$ http://municipiosverdes.com.br $>$. 
igualmente região-específico, para o desmatamento por Soares-Filho, Nesptad e Curran (2005) e Weinhold e Reis (2004). Ademais, outro importante determinante dos índices de desmatamento, identificado por Prates e Silva (2007), parece ser o preço da terra.

O presente trabalho, ainda que demande a consideração dos potenciais determinantes do desmatamento, direciona sua análise ao campo da avaliação de políticas públicas diretamente relacionadas ao controle do desmatamento, no qual o número de estudos ainda é bastante restrito. Entre estes, Viana et al. (2012) avaliaram o programa "Bolsa Floresta" onde famílias que vivem na floresta e são protegidas por lei recebem um valor mensal sob a condição de não desmatarem, afirmando ter eficácia limitada, dada a pouca fiscalização. Silva e Barreto (2014), por sua vez, analisaram o projeto "Pecuária Verde" da cidade de Paragominas, Pará, que consistia na maior fiscalização das áreas de pastagem, acordos com frigoríficos para compra de carne de fazendas regularizadas e confisco do gado de áreas desmatadas ilegalmente. Os autores concluíram que mesmo sendo localizado, o projeto foi relevante, uma vez que o município tinha grande participação no desmatamento total da Amazônia Legal.

Nesta pesquisa, entre os principais resultados, não foram encontradas evidências de que municípios participantes do Programa Munícipios Verdes (PMV), implementado em 2011, estejam reduzindo seus níveis de desmatamento. No entanto, ao considerar, como cenário alternativo, apenas municípios com melhores indicadores ambientais classificados como "consolidados" e "monitorados e sob controle" e que são participantes do PMV, isto é, aqueles que apresentavam taxas médias ou baixas de desmatamento no momento da criação do programa e atendiam em grande medida as exigências do comitê gestor do PMV, as evidências sugerem que estes estariam de fato conseguindo manter baixos seus níveis de desmatamento, estando elegíveis para receber todos os benefícios enfatizados pelo PMV, em contraposição àqueles com altas taxas de desmatamento.

O artigo está estruturado em quatro seções, sendo a primeira esta introdução. A Seção 2 descreve as principais características do programa a ser avaliado, fontes de dados utilizadas pelo estudo, e finaliza com a estratégia empírica adotada. Os resultados obtidos são apresentados na Seção 3. E, finalmente, na Seção 4, são apresentadas as considerações finais do artigo.

\section{Material e métodos}

\subsection{Programa Municípios Verdes (PMV)}

Conforme Whately e Campanili (2013), o PMV foi lançado oficialmente em março de 2011 por meio do Decreto Estadual no 54/2011 do governo do Pará, sob responsabilidade da Secretaria Extraordinária para Coordenação do Programa Municípios Verdes (SEPMV), diretamente vinculada à Casa Civil do estado. O programa surgiu como resposta do governo paraense às consequências a seu estado 
das políticas de redução do desmatamento por parte do Governo Federal e do Ministério Público Federal (MPF), que culminaram na inclusão de 17 municípios na lista de maiores desmatadores do Ministério do Meio Ambiente (MMA). Assim, o programa emergiu no contexto de duas iniciativas anteriores: o Plano de Prevenção e Controle do Desmatamento na Amazônia Legal (PPCDAM) do Governo Federal, lançado em 2004, e o projeto do município de Paragominas, Pará, denominado "Município Verde", criado em 2008. A influência do projeto paragominense decorre de seu sucesso: em 2010 o desmatamento na cidade já havia se reduzido em $90 \%$, sendo a primeira da Amazônia a deixar a "lista negra" do desmatamento do MMA.

Não existem requerimentos para ingresso no programa, bastando a assinatura de um TAC com o MPF, que abrange sete metas. O município signatário se compromete a cumprir, sob monitoramento da coordenação do PMV (WHATELY; CAMPANILI, 2013): 1) A elaboração de pacto local contra o desmatamento que abranja sociedade e governo municipal; 2) A criação de grupo de trabalho municipal visando combater o desmatamento; 3 ) O monitoramento em campo e a notificação ao PMV dos focos de desmatamento ilegal; 4) Manutenção do desmatamento anual abaixo de $40 \mathrm{~km}^{2}$, baseado nos critérios do Projeto de Estimativa do Desflorestamento da Amazônia do Instituto Nacional de Pesquisas Espaciais (Prodes/INPE); 5) $\mathrm{O}$ cadastro de $80 \%$ da área municipal no Cadastro Ambiental Rural (CAR), com exceção de terras indígenas e unidades de conservação; 6) A não aparição na lista do MMA de maiores desmatadores da Amazônia; 7) A introdução de noções de educação ambiental na rede municipal de ensino.

Por ser essencialmente voluntária, a adesão ao PMV é incentivada pelos potenciais benefícios da participação no programa e consequente redução do desmatamento, que são, de acordo com Whately e Campanili (2013): 1) Maior segurança jurídica, uma vez que as cidades ficariam livres de multas e embargos econômicos; 2) Valorização de mercado pelo aumento da participação de produtos com garantia de origem legal, os quais possuem maior valor, além de prioridade na compra por parte de grandes empresas do setor industrial e varejista; 3 ) Atração de investimentos decorrente da maior segurança jurídica; 4) Melhor acesso ao crédito e assistência técnica pelo fato de o Governo Federal priorizar municípios ambientalmente responsáveis, por exemplo, ao eliminar a exigência do Certificado de Cadastro do Imóvel Rural (CCIR), bastando, para a tomada de empréstimos, o protocolo do pedido de regularização do imóvel por parte do produtor nessas cidades; 5) Incentivos fiscais foram planejados pelo governo paraense desde o início do programa na forma de redução de impostos para os municípios participantes, já estando em vigor o chamado ICMS Verde, onde critérios ambientais relacionados às metas do PMV são utilizados para a distribuição dos recursos do estado para os municípios, embora não exija a participação no programa de fato (PEREIRA et al., 2014).

Além disso, o PMV classifica e atualiza, conforme metodologia específica de seu Comitê Gestor, os municípios participantes em cinco categorias que definem políticas específicas (WHATELY; CAMPANILI, 2013): 1) "Embargados” que corres- 
Santos; Almeida; Lacerda; Silva; Brito - Os impactos do Programa Municípios ...

pondem àqueles presentes na lista de maiores desmatadores da Amazônia divulgada pelo MMA; 2) "Sob pressão", que apresentam alto risco de desmatamento e de entrada na lista do MMA; 3 ) "Consolidados", que possuem médio risco de desmatamento, apresentando menos de $60 \%$ de cobertura vegetal e taxas menores de desmatamento; 4) "Base florestal", os quais têm baixo risco de desmatamento, possuem mais de $60 \%$ de cobertura vegetal e baixas taxas de desmatamento; 5) "Monitorados e sob controle", correspondendo aos municípios que atendem a todas as metas estabelecidas pelo Comitê Gestor do PMV, independente da proporção de cobertura vegetal.

Atualmente, os municípios classificados como "monitorados e sob controle" recebem a designação de "Municípios Verdes", conforme a base de dados do programa. Entretanto, planeja-se estabelecer critérios mais rigorosos para que esta classificação - de Município Verde - possua requisitos adicionais, como tempo de permanência na categoria "monitorados e sob controle" e aspectos relacionados à regularização do CAR (WHATELY; CAMPANILI, 2013).

Com o objetivo de avaliar a evolução do desmatamento entre os participantes e não participantes do $\mathrm{PMV}$, na análise de impacto foram considerados dois cenários no que tange ao grupo de tratamento. No cenário base, o grupo de tratamento corresponde aos municípios que haviam assinado o TAC com MPF até dezembro de 2012, ou seja, abrange todos os participantes, perfazendo um total de 92 . Como cenário alternativo, foram também analisados a evolução do desmatamento e o impacto em uma sub-amostra dos 92 municípios, correspondente a 47 classificados como "consolidados" ou "monitorados e sob controle". A lista completa de municípios participantes do PMV em dezembro de 2012 encontra-se em Whately e Campanili (2013).

\subsection{Avaliação de tratamento}

Em termos gerais, a avaliação de tratamento (ATE) implica na mensuração da diferença dos resultados de interesse (outcomes) entre agentes que participam de um tratamento (uma intervenção a ser avaliada) e outros que não participam, denominados "contra factuais" ou grupo de controle. Aplicando o conceito ao problema deste trabalho, formalmente, para um município $i$ em um período $t$, a média condicional do efeito de tratamento (ATE) é dada por:

$$
\mathrm{ATE}=\mathrm{E}\left[\mathrm{Y}_{\mathrm{i}}^{\mathrm{T}} \mid \mathrm{X}, \mathrm{D}_{\mathrm{i}}=1\right]-\mathrm{E}\left[\mathrm{Y}_{\mathrm{i}}^{\mathrm{C}} \mid \mathrm{X}, \mathrm{D}_{\mathrm{i}}=0\right]
$$

onde $\mathrm{Y}_{\mathrm{i}}$ é o resultado em potencial, impacto a ser medido, $\mathrm{D}_{\mathrm{i}}$ é uma variável binária que indica se o município recebe o tratamento $\left(\mathrm{D}_{\mathrm{i}}=1\right)$ ou se não participa do tratamento $\left(\mathrm{D}_{\mathrm{i}}=0\right)$. $\mathrm{O}$ vetor $\mathrm{X}$ representa um conjunto de covariadas comuns entre os municípios. 
Claramente, ambos os resultados não podem ser observados ao mesmo tempo para o mesmo município $i$, constituindo-se o principal problema analítico em avaliação de impacto (RAVALLION, 2008). A utilização de um resultado de um não participante qualquer como aproximação para o segundo termo em (1), , não é recomendada, uma vez que este possui características distintas daqueles que receberam o tratamento, gerando forte viés de seleção (ANGRIST; PISCHKE, 2009). Ressalta-se que as características que geram vieses influenciam apenas elementos observáveis afetando, portanto, o impacto da intervenção (CERDÁN-INFANTES; MAFFIOLI; UBFAL, 2008). Duflo, Glennerster e Kremer (2008) demonstram de que forma o viés de seleção pode afetar o resultado do tratamento através da adição e subtração do termo em (1), isto é:

$$
\begin{aligned}
\mathrm{ATE} & =\mathrm{E}\left[\mathrm{Y}_{\mathrm{i}}^{\mathrm{T}} \mid \mathrm{X}, \mathrm{D}_{\mathrm{i}}=1\right]-\mathrm{E}\left[\mathrm{Y}_{\mathrm{i}}^{\mathrm{C}} \mid \mathrm{X}, \mathrm{D}_{\mathrm{i}}=1\right]-\mathrm{E}\left[\mathrm{Y}_{\mathrm{i}}^{\mathrm{C}} \mid \mathrm{X}, \mathrm{D}_{\mathrm{i}}=0\right]+\mathrm{E}\left[\mathrm{Y}_{\mathrm{i}}^{\mathrm{C}} \mid \mathrm{X}, \mathrm{D}_{\mathrm{i}}=1\right] \\
& =\mathrm{E}\left[\mathrm{Y}_{\mathrm{i}}^{\mathrm{T}}-\mathrm{Y}_{\mathrm{i}}^{\mathrm{C}} \mid \mathrm{X}, \mathrm{D}_{\mathrm{i}}=1\right]+\mathrm{E}\left[\mathrm{Y}_{\mathrm{i}}^{\mathrm{C}} \mid \mathrm{X}, \mathrm{D}_{\mathrm{i}}=1\right]-\mathrm{E}\left[\mathrm{Y}_{\mathrm{i}}^{\mathrm{C}} \mid \mathrm{X}, \mathrm{D}_{\mathrm{i}}=0\right]
\end{aligned}
$$

Neste caso, o primeiro termo em (2) é o efeito do tratamento médio sobre o grupo dos tratados (ATET) e o segundo e terceiro termo correspondem ao viés de seleção, o qual captura potenciais diferenças entre grupos de tratamento e de controle. Consequentemente, a estimação do ATE - usando o modelo análogo em (2) - irá produzir estimativas viesadas do verdadeiro impacto da intervenção.

De acordo com Duflo, Glennerster e Kremer (2008), um experimento aleatório assume que todos os participantes são elegíveis para receber o benefício de uma intervenção. Assim, recebendo ou não o tratamento, os resultados serão potencialmente independentes da intervenção e, consequentemente, o viés da seleção deixa de ser um problema (ANGRIST; PISCHKE, 2009). A randomização da intervenção implica que os últimos dois termos em (2) sejam nulos, ou seja, , sendo o parâmetro de interesse ATE em (2) finalmente identificado.

Entretanto, na prática, experimentos aleatórios em intervenções socioeconômicas são de difícil aplicação por serem muito dispendiosos e de difícil controle. Assim, a maioria das avaliações de impacto recentes têm sido executadas através de desenho amostrais denominados "quasi experimental", mensurando apenas os efeitos do tratamento médio sobre o grupo dos tratados (ATET) (RAVALLION, 2008). Neste caso, o impacto através do ATET é dado pelo primeiro termo na parte direita em (2) e é estimado como:

$$
\mathrm{ATET}=\mathrm{E}\left[\mathrm{Y}_{\mathrm{i}}^{\mathrm{T}}-\mathrm{Y}_{\mathrm{i}}^{\mathrm{C}} \mid \mathrm{X}, \mathrm{D}_{\mathrm{i}}=1\right]=\mathrm{E}\left[\mathrm{Y}_{\mathrm{i}}^{\mathrm{T}} \mid \mathrm{X}, \mathrm{D}_{\mathrm{i}}=1\right]-\mathrm{E}\left[\mathrm{Y}_{\mathrm{i}}^{\mathrm{C}} \mid \mathrm{X}, \mathrm{D}_{\mathrm{i}}=1\right]
$$

Deve notar-se que, novamente, os resultados não são observados simultaneamente e, como consequência, a situação contra factual $\mathrm{E}\left[\mathrm{Y}^{\mathrm{C}} \mid \mathrm{X}, \mathrm{D}=1\right]$ precisa ser 
Santos; Almeida; Lacerda; Silva; Brito - Os impactos do Programa Municípios ...

construída (CALIENDO; KOPEINIG, 2008). O propensity score matching (PSM) ou emparelhamento por escore de propensão - a ser apresentado em mais detalhes a seguir - é o método que não somente permite a construção de um grupo contra factual - ou de controle -, mas também auxilia na eliminação de possíveis vieses de seleção amostral nas variáveis observadas (ROSENBAUM; RUBIM, 1983; IMBENS; WOOLDRIDGE, 2008).

\subsection{Emparelhamento por escore de propensão}

O principal objetivo do método pelo PSM é gerar um "escore" igual ao da probabilidade de recebimento de tratamento, considerando ambos tratados e não tratados a partir de um determinado conjunto de covariadas pré-determinadas que possam identificar a elegibilidade (probabilidade) de participar do programa (CAMERON; TRIVEDI, 2005). Em princípio, qualquer estimação de regressão binária (logit, probit ou mínimo quadrados ordinários) poderia ser utilizada para mensurar essa probabilidade, todavia regressões logísticas têm sido mais utilizadas para esse fim (BECKER; ICHINO, 2002).

A validade da abordagem do PSM requer que duas condições principais relacionadas aos grupos de tratamento e de controle sejam respeitadas. ${ }^{3}$ Em primeiro lugar, Rosenbaum e Rubin (1983) referem-se à hipótese de independência condicional (HIC), que implica que potenciais resultados, $Y_{i}$, são independentes do tratamento, $\mathrm{D}_{\mathrm{i}}$, dado um conjunto de variáveis observáveis. Isto pode ser representado como:

$$
\mathrm{Y}_{\mathrm{i}=\{\mathrm{D}=1,0\}} \mathrm{D}_{\mathrm{i}} \mathrm{X} \text {. }
$$

Alternativamente, Rosenbaum e Rubin (1983) também mostram que o vetor $\mathrm{X}$ pode ser substituído pelo escore de propensão $\mathrm{p}(\mathrm{x})$ ou

$$
\mathrm{Y}_{\mathrm{i}=\{\mathrm{D}=1,0\}} \mathrm{D}_{\mathrm{i}} \mathrm{p}_{\mathrm{i}}(\mathrm{X}) \text {. }
$$

O uso de um escore de propensão (um vetor unidimensional) é uma ferramenta útil, uma vez que evita o problema comum da "curse of dimensionality" na operacionalização do pareamento (CAMERON; TRIVEDI, 2005).

A segunda hipótese requer que o suporte comum (condição de sobreposição) seja imposto, isto é,

$$
0<\mathrm{P}\left(\mathrm{D}_{\mathrm{i}}=1,0 \mathrm{p}_{\mathrm{i}}(\mathrm{X})\right)<1
$$

\footnotetext{
3 As provas formais das duas hipóteses podem ser encontradas em Rosenbaum e Rubin (1983).
} 
Caliendo e Kopeinig (2008) apontam que o condicionamento ao vetor $\mathrm{X}$ ou ao escore de propensão $\mathrm{p}(\mathrm{X})$ assegura que os grupos de tratados e de controle encontram-se dentro do mesmo intervalo, facilitando o emparelhamento entre tratamento e controle, evitando, assim, pareamentos inadequados.

Após estimar o modelo de escolha binária incluindo participantes e não participantes, e assumindo que as duas condições apresentadas acima sejam respeitadas, o próximo passo é realizar o pareamento entre os grupos de tratamento e controle por meio dos escores de propensão (probabilidades esperadas), dessa forma gerando uma situação contra factual ("de quase clones perfeitos") (KHANDKER; KOOLWAL; SAMAD, 2009). Na literatura de avaliação de impacto, diversas técnicas de pareamento estão disponíveis (CAMERON; TRIVEDI, 2005). As técnicas mais frequentemente empregadas, e a serem utilizadas neste trabalho, seguindo Cameron e Trivedi (2005), Caliendo e Kopeinig (2008) são descritas brevemente a seguir.

A primeira e mais direta técnica de emparelhamento corresponde ao "vizinho mais próximo" (VMP), que pode ser executada com ou sem reposição. ${ }^{4}$ Baseada nos escores de propensão, a técnica VMP seleciona, para cada município participante $i$, o mais próximo não participante $j$ (pareamento um-a-um). Matematicamente, existe um $\mathrm{A}_{\mathrm{i}}(\mathrm{p}(\mathrm{x}))=\left\{\mathrm{j}\left|\min \mathrm{j} \| \hat{p}_{i}-\hat{p}_{j}\right| \mid\right\}$, em que ||$\|$ denota a distância euclidiana entre os escores de propensão $\hat{p}$.

A segunda técnica de pareamento, vizinho mais próximo com distância pré-definida através de um calibre (caliper), é uma extensão da técnica VMP, em que para todo município participante $i$, um não participante $j$ com um escore de propensão estimado que se encontra dentro do caliper $r$, é escolhido. A amostra pareada é, então, dada pelo conjunto $\mathrm{A}_{\mathrm{i}}(\mathrm{p}(\mathrm{x}))=\left\{\hat{p}_{j}||\left|\hat{p}_{i}-\hat{p}_{j}\right| \mid<r\right\}$.

Por serem baseados na distância mínima entre dois escalares (os escores de propensão), estes dois algoritmos de emparelhamento são amplamente utilizados devido à fácil implementação, sendo ambos mais apropriados quando o tamanho da amostra é grande e existe um amplo conjunto de covariadas observadas disponível, de modo a prevenir a chamada "curse of dimensionality" (ROSENBAUM; RUBIN, 1983). Alternativamente, o método de Mahalanobis (conhecido por emparelhamento covariado ou covariate matching) é também baseado em distâncias euclidianas, mas não considera os escores de propensão, postulando que se há dois vetores $n$-dimensionais - um para o grupo tratado $\left(\mathrm{x}^{\mathrm{i}}\right)$ e outro para o grupo de controle $\left(x^{j}\right)$ - então a amostra pareada é constituída por um conjunto $A_{i}\left(x^{i}, x^{j}\right)=\left(x^{i}-x^{j}\right)^{\prime}$ $\mathrm{C}^{-1}\left(\mathrm{x}^{\mathrm{i}}-\mathrm{x}^{\mathrm{j}}\right)$, sendo $\mathrm{C}^{-1}$ a matriz de covariância da amostra que pondera as variáveis de pareamento do conjunto completo de indivíduos de controle e de tratamento. Embora o aumento do número de covariadas torne mais difícil para a unidade de tratamento "encontrar" sua unidade de controle mais próxima, devido à "curse of dimensionality", caso haja a necessidade de parear características as mais próximas

4 Austin (2014) desencoraja o uso do emparelhamento com reposição, porque existem evidências que produziria variâncias maiores das estimativas de impacto do que o emparelhamento sem reposição. 
possível, então a fórmula de Mahalanobis para a realização do emparelhamento covariado pode ser muito útil (D’AGOSTINO, 1998).

Os três algoritmos descritos acima têm uma limitação comum: a possibilidade de que algumas observações do grupo de não tratados eventualmente sejam descartadas durante o emparelhamento, o que pode ser um problema quando a amostra é pequena. Como alternativa, Heckman et al. (1997) propuseram estimar o efeito do tratamento sobre a população tratada através da ponderação da variável de interesse considerando todos os indivíduos dos grupos de tratados e não tratados por meio de uma regressão não paramétrica conhecida por Nadaraya-Watson na qual os escore de propensão são usados como pesos. Esta abordagem ficou conhecida como estimador de emparelhamento kernel de Heckman e pode ser expressa como:

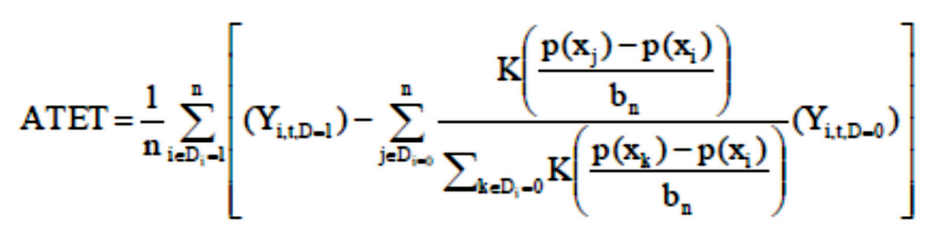

em que $\mathrm{Y}_{\mathrm{it}}$ é o outcome, $\mathrm{K}(\cdot)$ é a função kernel, $\mathrm{p}(\mathrm{x})$ é o escore de propensão gerado pelo modelo logit, e $\mathrm{b}_{\mathrm{n}}$ é a banda (bandwidth) ou parâmetro de suavização. ${ }^{5}$

Independentemente da técnica utilizada, é imperativo, após o pareamento, verificar se o balanceamento das covariadas consideradas na estimação da probabilidade de participar do programa é satisfeito, uma vez que o mesmo é fundamental para a redução de vieses de seleção amostral e garante que comparáveis possam ser de fato comparados. Nosso critério é baseado em viés padronizado menor que $20 \%{ }^{6}$ e p-values entre tratados e controles não menor que $10 \%$ do nível de significância estatística (ROSENBAUM; RUBIN, 1983; HEINRICH; MAFFIOLI; VÁZQUEZ, 2010). Caso não existam diferenças estatísticas entre nenhuma das informações das variáveis disponíveis para unidades tratadas e não tratadas, pode-se dizer que conseguiu-se aproximar a uma situação de "quase clones perfeitos" permitindo-se que dessa forma o real valor do impacto do tratamento possa ser auferido.

5 A regressão local linear é uma versão da regressão não paramétrica do emparelhamento kernel proposto por Heckman et al., (1997) e também será utilizada pelo presente trabalho. Detalhes desses métodos podem ser encontrados em Caliendo e Kopeinig (2008).

6 O viés padronizado é o tamanho da diferença das médias entre as covariadas que fazem parte do tratamento e aquelas que não fazem parte do tratamento, dividido pela soma da raiz da quadrada das suas variâncias (HEINRICH; MAFFIOLI; VÁSQUEZ, 2010). 


\subsection{Combinando PSM e diferença nas diferenças (DD)}

Como já pontuado, a avaliação precisa e robusta de uma intervenção é possível apenas se as características dos não participantes encontram-se bem pareadas com aquelas dos participantes. Embora o emparelhamento possa eliminar ou reduzir substancialmente vieses decorrentes de características observadas, é possível que outros vieses de características invariantes no tempo e não observadas dos municípios se mantenham (GERTLER et al., 2011; MAFFIOLI et al., 2013). Como dados em painel estão disponíveis para este estudo, pode-se combinar o estimador de diferença nas diferenças (DD) para estimar o ATET com os escores de propensão a partir de diversos algoritmos de pareamento ou simplesmente utilizando as covariadas (covariate matching) (KHANDKER; KOOLWAL; SAMAD, 2009; BRAVO-URETA, 2014). A abordagem DD, como inicialmente sugerido por Heckman et al. (1997), mede a diferença entre o resultado esperado dos grupos de tratamento e de controle no período de referência e a diferença no resultado entre os grupos de tratamento e controle no fim do tratamento (RAVALLION, 2008). O efeito médio do tratamento sobre o tratado individual $i$, utilizando o DD conjuntamente com o PSM pode ser expresso como:

$$
D_{i}=\left(Y_{i, t}^{T}-Y_{i, t-1}^{T}\right)-\sum_{j \in c} \omega(i, j)\left(Y_{i, t}^{C}-Y_{i, t-1}^{C}\right)
$$

onde $\omega(\mathrm{i}, \mathrm{j})$ é o peso (utilizando PSM ou emparelhamento covariado), dado o $j$-ésimo indivíduo do controle pareado com o $i$-ésimo indivíduo tratado, $t$ é momento final do tratamento, $t-1$ é o período de referência, e $\mathrm{T}$ e $\mathrm{C}$ indicam tratamento ou controle, respectivamente (KHANDKER; KOOLWAL; SAMAD, 2009).

\subsection{Fontes de dados}

É importante ilustrar que dentro da literatura de avaliação de impacto, que faz uso de método do emparelhamento por escore de propensão, é mais apropriado escolher determinantes que sejam independentes do tratamento, de modo a satisfazer a hipótese de independência condicional (SMITH, 1997; CALIENDO; KOIPEINIG, 2008). Procurou-se, então, seguir ao máximo esses critérios baseando-se na intuição econômica e nos trabalhos empíricos consultados. Esta escolha é complexa, uma vez que que não existem critérios claramente estabelecidos referentes a elegibilidade de participação no PMV.

Todas as variáveis utilizadas na análise estão definidas na Tabela 1. Quanto às fontes, além da lista de municípios signatários do TAC com o MPF (participantes do programa), retirada de Whately e Campanili (2013), do Instituto Brasileiro de Geografia e Estatística (IBGE, 2015) foram obtidos os dados referentes à popu- 
lação, número de cabeças de gado em 2012 (Produção Pecuária Municipal), área plantada de soja em 2012 (Produção Agrícola Municipal), volume de madeira em tora produzida em 2012 (Produção da Extração Vegetal e da Silvicultura), e estabelecimentos por condição do produtor perante à propriedade da terra do Censo Agropecuário de 2006. A área dos municípios da Amazônia Legal e a área desmatada anual foram obtidas a partir do Prodes/INPE (2015). Finalmente, o partido governante corresponde ao resultado das Eleições Municipais de 2008 disponibilizado pelo Tribunal Superior Eleitoral.

Como evidenciado pela literatura, a área e população do município somada ao aumento da atividade agropecuária tendem a pressionar os níveis de desmate, enquanto sua estrutura fundiária poderia representar modelos produtivos com diferentes impactos ambientais, bem como associar-se a conflitos por terra. Finalmente, considera-se o aspecto político, na medida em que diferentes níveis de articulação entre as esferas de poder poderiam ser relevantes à decisão de entrar no programa, e a produção de madeira no ano de referência.

7 Pressupõe-se que a estrutura fundiária não se alterou significativamente até o período de análise dessa pesquisa. 


\section{Quadro 1 - Definição das Variáveis}

\begin{tabular}{|c|c|c|}
\hline Variável & Unidade & Definição \\
\hline Desmat_2013 & $\mathrm{km}^{2}$ & Variação do desmatamento entre 2012 e 2013 \\
\hline Desmat_2012 & $\mathrm{km}^{2}$ & Variação do desmatamento entre 2011 e 2012 \\
\hline Desmat_2011 & $\mathrm{km}^{2}$ & Variação do desmatamento entre 2010 e 2011 \\
\hline Consoli_2012 & Binária & $\begin{array}{l}1 \text { se o município faz parte do programa município verde dentro da } \\
\text { categoria "consolidados" ou "monitorados e sob controle" em } 2012\end{array}$ \\
\hline PMV_2012 & Binária & $\begin{array}{l}1 \text { se o município assinou o TAC com o MPF, ou seja, faz parte } \\
\text { PMV }\end{array}$ \\
\hline AreaKm2 & $\mathrm{km}^{2}$ & Área do município em km² \\
\hline Pop & Quantidade & População urbana e rural do município \\
\hline Boi & Quantidade & Cabeças de gado \\
\hline Soja & ha & Quantidade de soja plantada \\
\hline Propriet & Número & $\begin{array}{l}\text { Quantidade de estabelecimentos cujo produtor estava na condição } \\
\text { de proprietário }\end{array}$ \\
\hline Parceiro & Número & $\begin{array}{l}\text { Quantidade de estabelecimentos cujo produtor estava na condição } \\
\text { de parceiro }\end{array}$ \\
\hline Ocupante & Número & $\begin{array}{l}\text { Quantidade de estabelecimentos cujo produtor estava na condição } \\
\text { de ocupante }\end{array}$ \\
\hline Assenta & Número & $\begin{array}{l}\text { Quantidade de estabelecimentos cujo produtor estava na condição } \\
\text { de assentado }\end{array}$ \\
\hline PT_2008 & Binária & 1 se município é governado pelo PT \\
\hline PSDB_2008 & Binária & 1 se município é governado pelo PSDB \\
\hline DEM_2008 & Binária & 1 se município é governado pelo Democratas \\
\hline PMDB_2008 & Binária & 1 se município é governado pelo PMDB \\
\hline PP_2008 & Binária & 1 se município é governado pelo PP \\
\hline PSB_2008 & Binária & 1 se município é governado pelo PSB \\
\hline POUTROS & Binária & 1 se município é governado por outros partidos \\
\hline MADEI_2012 & $\mathrm{m}^{3}$ & Volume em $\mathrm{m}^{3}$ de toras de madeira produzidas \\
\hline
\end{tabular}

Fonte: Elaborado pelos autores

\section{Resultados e discussão}

Previamente ao objetivo principal do trabalho de avaliar os impactos do PMV, é interessante observar a evolução do desmatamento na Amazônia Legal, entre 2001 e 2013, para os municípios que vieram a participar do programa conjuntamente àqueles que não participaram. $\mathrm{O}$ gráfico 1 sobrepõe, em índice, o comportamento 
da variação da área desmatada nos 92 municípios que faziam parte do PMV no ano base de 2012, e todos aqueles que não participavam do programa. Ao longo do período recente, ocorreu uma desaceleração bastante expressiva do processo de desmate. É possível também observar que o comportamento das séries é semelhante, entretanto a variação da área desmatada entre os participantes do PMV se manteve abaixo do restante da Amazônia Legal até 2005, quando ocorreu uma inversão. As duas séries voltaram a convergir a partir de 2011, terminando 2013 em nível muito próximo.

Gráfico 1 - Evolução do índice $(2011 / 12=100)$ do desmatamento entre os municípios participantes do PMV e aqueles não participantes

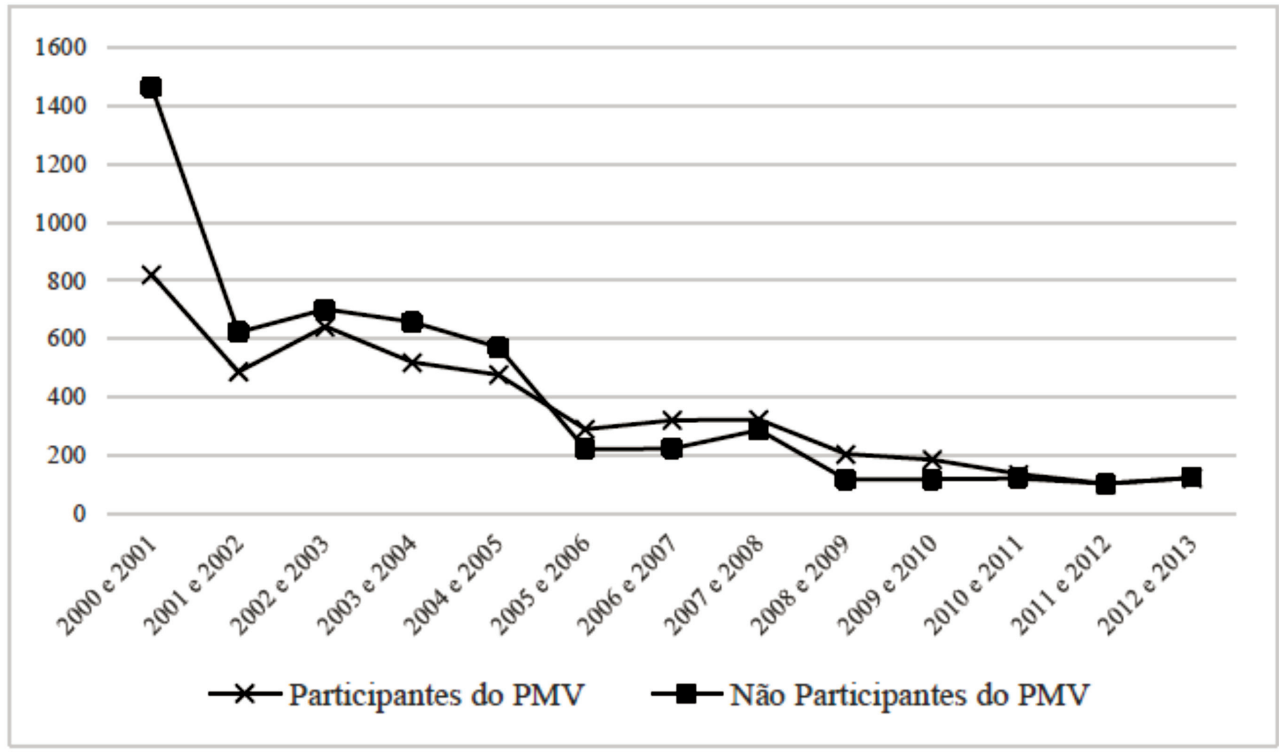

Fonte: Elaborado pelos autores a partir dos dados do Prodes/INPE (2015).

O gráfico 2, por sua vez, ilustra a evolução do desmatamento no conjunto de municípios considerados "consolidados" ou "monitorados e sob controle" dentro do PMV, em um total de 47, simultaneamente com seu conjunto complementar de 735 municípios no universo de municípios da Amazônia. É importante observar que entre os municípios que não são classificados como "consolidados" ou "monitorados e sob controle" há tanto participantes, quanto não participantes do PMV. Neste caso, é possível perceber características distintas do gráfico 1, iniciando pela desaceleração do desmatamento que é mais forte nos municípios classificados como "consolidados" ou "monitorados e sob controle" em relação a todos os outros da Amazônia Legal. Assim, a variação anual da área desmatada entre 2012 e 2013 nos municípios "consolidados" ou "monitorados e sob controle" corresponde a 5,4\% 
daquela observada entre 2000 e 2001, enquanto o restante dos municípios tem um aumento da área desmatada entre 2012 e 2013 que representa 10,2\% daquele observado entre 2000 e 2001.

Gráfico 2 - Evolução do índice $(2012 / 13$ = 100) desmatamento entre os municípios participantes do Programa Municípios Verdes (somente municípios consolidados e monitorados e sob controle) e aqueles não "consolidados" e não "monitorados e sob controle" do PMV e não participantes

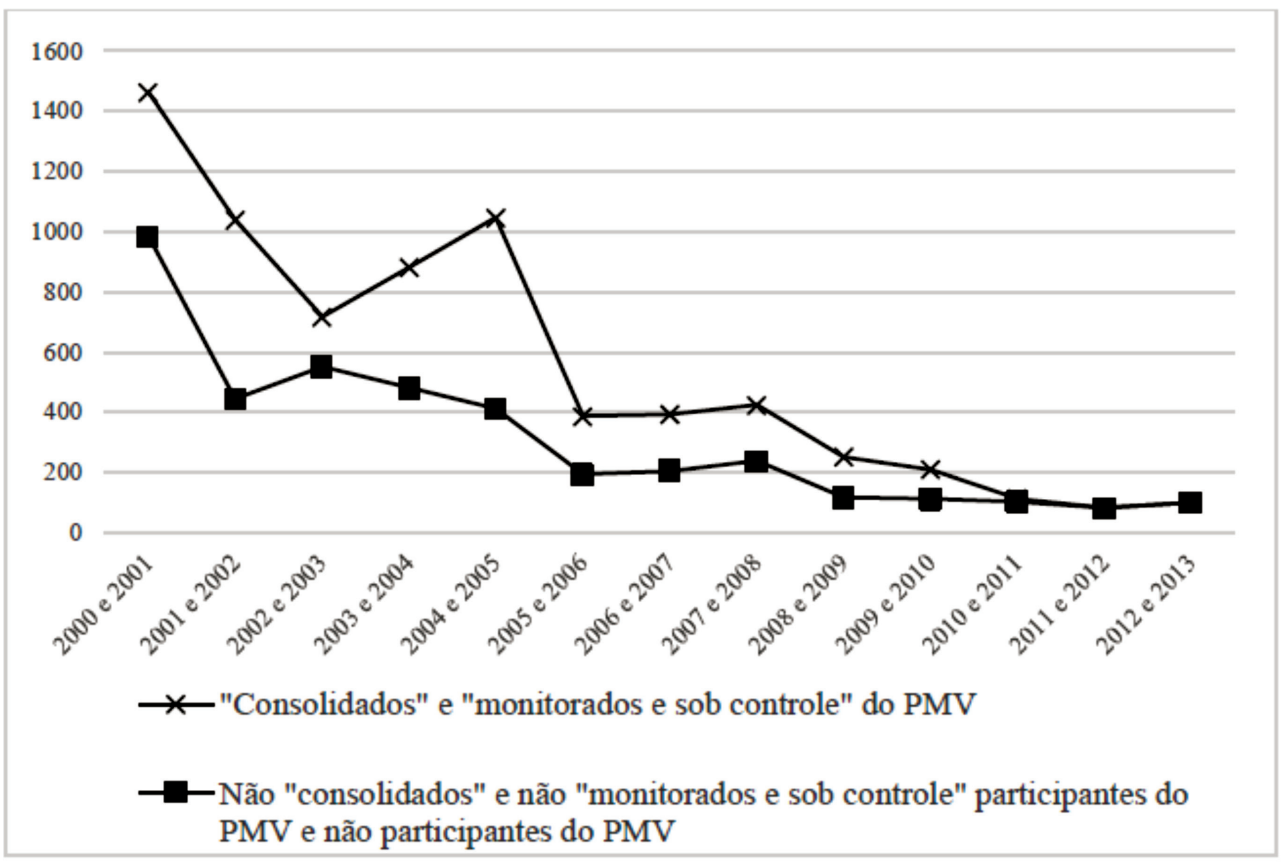

Fonte: Elaborado pelos autores a partir dos dados do Prodes/INPE (2015).

Como descrito na metodologia, para comparar o efeito real do Programa Municípios Verdes sobre a evolução do desmatamento, é necessária a existência um grupo de controle, ou seja, um conjunto de municípios fora do programa, mas que possuam as mesmas características geográficas, econômicas, sociais, políticas etc. daqueles que participam. Como, a adesão ao PMV é voluntária, de forma que não há critérios de elegibilidade à participação de determinado município, bastando a assinatura do TAC com MPF, poder-se-ia questionar se a assinatura do acordo é de fato suficiente para avaliar o programa. Esse é um ponto importante já que um dos objetivos de utilizar as técnicas de emparelhamento por escore de propensão é apenas identificar ou medir os efeitos dessas características citadas acima sobre a probabilidade de tratamento (SMITH, 1997; CALIENDO; KOPEINIG, 2008). Como já mencionado, procurou-se, então, escolher características socioeconômi- 
Santos; Almeida; Lacerda; Silva; Brito - Os impactos do Programa Municípios ...

cas e geográficas visando identificar municípios comparáveis fora do programa com aqueles que participam do PMV.

A tabela 1 reporta as médias e desvios-padrão das variáveis usadas para medir a probabilidade de participar do PMV entre todos os municípios da Amazônia Legal (participantes e não participantes). No cenário base, foi avaliado o impacto nos 92 participantes que tinham acordo como o MPF, tendo sido escolhido o ano base de 2012 para a análise visando captar algum impacto a partir da implementação do PMV em março de 2011 e também por ser o ano de referência da primeira divulgação da situação dos municípios em relação às metas do programa. As duas últimas colunas da tabela 1 contém estatísticas (teste t-student e a diferença de viés padronizado em $\%$ ) que devem ser utilizadas para comparar os grupos de tratados e não tratados no que se refere às características observáveis antes e depois do emparelhamento.

Tabela 1 - Comparação dos Grupos Antes do Emparelhamento dos Participantes do Programa Municípios Verdes (PMV) versus Não Participantes do PMV (Ano Base: 2012)

\begin{tabular}{|c|c|c|c|c|c|c|}
\hline \multirow[b]{2}{*}{ Variável } & \multicolumn{2}{|c|}{ Tratamento } & \multicolumn{2}{|c|}{ Controle } & \multirow{2}{*}{$\begin{array}{c}\text { Estatística - t } \\
\text { Duas } \\
\text { Amostras }\end{array}$} & \multirow{2}{*}{$\begin{array}{c}\text { Viés } \\
\text { Padronizado } \\
\text { em \% }\end{array}$} \\
\hline & Média & $\mathrm{DP}$ & Média & DP & & \\
\hline $\log$ pop & 9.58 & 0.85 & 9.61 & 1.10 & 0.3 & -3.98 \\
\hline $\log \mathrm{km} 2$ & 8.48 & 1.36 & 7.70 & 1.33 & $-5.2 \% * \%$ & 57.45 \\
\hline $\log$ Boi & 10,65 & 1,64 & 10,34 & 2,04 & $-1,40$ & 16,78 \\
\hline $\log$ Soja & 1,50 & 3,14 & 2,63 & 4,16 & $2,51 * 6$ & $-30,69$ \\
\hline log Propriet & 6,79 & 0,97 & 6,09 & 0,97 & $-6,58 * * *$ & 73,05 \\
\hline $\log$ Assenta & 3,21 & 1,96 & 2,60 & 2,02 & $-2,70 * * *$ & 30,27 \\
\hline log Parceiro & 1,52 & 1,38 & 1,62 & 1,54 & 0,60 & $-6,97$ \\
\hline log Ocupante & 3,13 & 1,77 & 2,89 & 1,99 & $-1,11$ & 12,84 \\
\hline PT_2008 & 0,23 & 0,42 & 0,10 & 0,30 & $-3,59 * * *$ & 34,55 \\
\hline PSDB_2008 & 0,08 & 0,27 & 0,09 & 0,29 & 0,56 & $-6,48$ \\
\hline DEM_2008 & 0,04 & 0,21 & 0,11 & 0,31 & $1,92 *$ & $-24,28$ \\
\hline PMDB_2008 & 0,24 & 0,43 & 0,19 & 0,39 & $-1,12$ & 11,99 \\
\hline PP_2008 & 0,02 & 0,15 & 0,07 & 0,26 & $1,87 *$ & $-24,59$ \\
\hline PSB_2008 & 0,04 & 0,21 & 0,03 & 0,18 & $-0,58$ & 6,07 \\
\hline log madei_2012 & 9,58 & 2,50 & 8,03 & 3,24 & $-4,42 * * *$ & 53,56 \\
\hline Observações & \multicolumn{2}{|c|}{92} & \multicolumn{2}{|c|}{690} & & \\
\hline
\end{tabular}

Fonte: Elaborado pelos autores.

Nota: $* *, * *, *$ Significante ao nível de $1 \%, 5 \%$ e $10 \%$, respectivamente. 
Para verificar a existência de diferenças entre os grupos de controle e tratamento, tornou-se padrão os critérios de medida de diferença padronizada - não superior a $20 \%$, em valor absoluto - e testes t-student - não inferiores ao nível de 10\% de significância estatística (ROSENBAUM; RUBIN, 1983; HEINRICH; MAFFIOLI; VÁZQUEZ, 2010). Seguindo estes dois critérios, como pode ser observado na Tabela 1, oito variáveis demonstraram tal distorção em nossa amostra.

Alternativamente, uma sub-amostra do PMV, com apenas os municípios classificados como "consolidados" ou "monitorados e sob controle" em 2012 que tiveram o acordo com o MPF, totalizando 47, também teve seu impacto avaliado. A tabela 2 reporta as médias e desvios-padrão entre tratamento e controle para essa sub-amostra, bem como testes $t$-student e diferença do viés padronizado em $\%$. Observa-se que sete variáveis do grupo de controle são estatisticamente diferentes do grupo de tratamento.

Tabela 2 - Comparação dos grupos antes do emparelhamento entre os participantes do PMV - Categorias "consolidados" e "monitorados e sob controle" versus não "consolidados", "não monitorados e sob controle” do PMV e não participantes do PMV (Ano Base: 2012)

\begin{tabular}{|c|c|c|c|c|c|c|}
\hline \multirow[b]{2}{*}{ Variável } & \multicolumn{2}{|c|}{ Tratamento } & \multicolumn{2}{|c|}{ Controle } & \multirow{2}{*}{$\frac{\text { Duas Amostras }}{\text { Estatística - t }}$} & \multirow{2}{*}{$\begin{array}{c}\text { Viés } \\
\begin{array}{c}\text { Padronizado } \\
\text { em \% }\end{array} \\
\end{array}$} \\
\hline & Média & DP & Média & $\mathrm{DP}$ & & \\
\hline $\log$ pop & 9.37 & 0.74 & 9.63 & 1.09 & 1.58 & -27.26 \\
\hline $\log \mathrm{km} 2$ & 7.70 & 0.97 & 7.80 & 1.37 & 0.47 & -8.10 \\
\hline $\log$ Boi & 10.515 & 1.690 & 10.339 & 2.043 & -0.58 & 9.42 \\
\hline $\log$ Soja & 1.225 & 3.031 & 2.626 & 4.162 & $2.27 * *$ & -38.48 \\
\hline $\log$ Propriet & 6.596 & 0.796 & 6.085 & 0.969 & $-3.53 * * *$ & 57.59 \\
\hline log Assenta & 2.936 & 1.882 & 2.604 & 2.024 & -1.09 & 17.01 \\
\hline log Parceiro & 1.089 & 1.032 & 1.620 & 1.543 & $2.33 \% *$ & -40.51 \\
\hline log Ocupante & 2.556 & 1.935 & 2.889 & 1.988 & 1.11 & -16.99 \\
\hline PT_2008 & 0.234 & 0.428 & 0.101 & 0.302 & $-2.82 * * *$ & 35.79 \\
\hline PSDB_2008 & 0.085 & 0.282 & 0.094 & 0.292 & 0.21 & -3.17 \\
\hline DEM_2008 & 0.021 & 0.146 & 0.107 & 0.310 & $1.89 *$ & -35.52 \\
\hline PMDB_2008 & 0.255 & 0.441 & 0.190 & 0.392 & -1.10 & 15.69 \\
\hline PP_2008 & 0.043 & 0.204 & 0.074 & 0.262 & 0.80 & -13.36 \\
\hline PSB_2008 & 0.064 & 0.247 & 0.032 & 0.176 & -1.17 & 14.90 \\
\hline log madei_2012 & 8.794 & 2.631 & 8.030 & 3.236 & -1.58 & 25.89 \\
\hline Observações & \multicolumn{2}{|c|}{47} & \multicolumn{2}{|c|}{735} & & \\
\hline
\end{tabular}

Fonte: Elaborado pelos autores.

Nota: $* * \%, *$ Significante ao nível de $1 \%, 5 \%$ e $10 \%$, respectivamente. 
A tabela 3 reporta as estimativas e efeitos marginais (valor das probabilidades) do modelo logit para as duas amostras. Uma amostra considera a variável dependente igual a 1 se o município participava do PMV e tinha acordo como MPF e a zero, caso contrário. $\mathrm{Na}$ segunda amostra, a variável dependente é igual a 1 se o município era classificado como "consolidado" ou "monitorado e sob controle" dentro do PMV e tinha acordo como MPF ou a zero, caso contrário. Todos os 782 municípios da Amazônia Legal foram usados na análise dos logits. Em ambas as regressões, a hipótese nula de que todos os coeficientes são iguais a zero foi rejeitada consistentemente ao nível de 1\% de significância. De forma geral, os dois modelos apresentaram bom grau de robustez acerca do nível de significância de seus coeficientes individualmente. Pode-se constatar, por exemplo, que o aumento do número de cabeças de gado, do número de estabelecimentos operados por seus proprietários e da produção de madeira aumentam a probabilidade de o município ter um acordo com o MPF e participar do PMV. Resultado similar acerca dos sinais destes coeficientes foi observado para o modelo que considerou apenas municípios "consolidados" e "monitorados e sob controle".

Tabela 3 - Resultados do Modelo Logit

\begin{tabular}{|c|c|c|c|c|}
\hline \multirow[b]{2}{*}{ Variáveis } & \multicolumn{2}{|c|}{ PMV_2012 } & \multicolumn{2}{|c|}{ Mun, Consol_2012, Monit_2012 } \\
\hline & Coeficiente & $\begin{array}{c}\text { Efeitos } \\
\text { Marginais }\end{array}$ & Coeficiente & Efeitos Marginais \\
\hline \multirow[t]{2}{*}{ Log de área km2 } & $0.30922 * * \%$ & 0.0190 & -0.23768 & -0.00683 \\
\hline & $(0.10776)$ & & $(0.15392)$ & \\
\hline \multirow[t]{2}{*}{ Log de pop } & -0.08187 & -0.0050 & $-0.24923 * \%$ & -0.00716 \\
\hline & $(0.09918)$ & & $(0.12538)$ & \\
\hline \multirow[t]{2}{*}{ Log de Boi } & $0.10911 *$ & 0.0067 & 0.04868 & 0.00140 \\
\hline & $(0.05945)$ & & $(0.07779)$ & \\
\hline \multirow[t]{2}{*}{ Log de Soja } & $-0.13337 * * *$ & -0.0082 & $-0.13347^{* * *}$ & -0.00384 \\
\hline & $(0.03221)$ & & $(0.05081)$ & \\
\hline \multirow[t]{2}{*}{ Log de propriet } & $0.99180 * \cdots *$ & 0.0609 & $1.11957 \% * *$ & 0.03218 \\
\hline & $(0.19933)$ & & $(0.25521)$ & \\
\hline \multirow[t]{2}{*}{ Log de assenta } & -0.05314 & -0.0033 & -0.01716 & -0.00049 \\
\hline & $(0.06486)$ & & $(0.08047)$ & \\
\hline \multirow[t]{2}{*}{ Log de parceiro } & $-0.38617 \div \cdots *$ & -0.0237 & $-0.56727 * \cdots \cdots$ & -0.01630 \\
\hline & $(0.13529)$ & & $(0.16776)$ & \\
\hline \multirow[t]{2}{*}{ Log de ocupante } & -0.05582 & -0.0034 & -0.12893 & -0.00371 \\
\hline & $(0.10017)$ & & $(0.12452)$ & \\
\hline
\end{tabular}


(continua)

\begin{tabular}{|c|c|c|c|c|}
\hline PT_2008 & $0.81448 * \%$ & 0.0661 & $1.01105 \%$ & 0.04298 \\
\hline & $(0.35004)$ & & $(0.46402)$ & \\
\hline \multirow[t]{2}{*}{ PSDB_2008 } & -0.11744 & -0.0069 & 0.26453 & 0.00843 \\
\hline & $(0.51003)$ & & $(0.65122)$ & \\
\hline \multirow[t]{2}{*}{ DEM_2008 } & $-1.00602 *$ & -0.0445 & -1.42114 & -0.02555 \\
\hline & $(0.59604)$ & & $(1.08319)$ & \\
\hline \multirow[t]{2}{*}{ PMDB_2008 } & 0.27543 & 0.0182 & 0.59273 & 0.02040 \\
\hline & $(0.31530)$ & & $(0.41684)$ & \\
\hline \multirow[t]{2}{*}{ PP_2008 } & -1.07514 & -0.0452 & -0.25517 & -0.00662 \\
\hline & $(0.79901)$ & & $(0.81368)$ & \\
\hline \multirow[t]{2}{*}{ PSB_2008 } & 0.25970 & 0.0177 & 0.82846 & 0.03482 \\
\hline & $(0.61785)$ & & $(0.68511)$ & \\
\hline \multirow[t]{2}{*}{$\begin{array}{c}\text { Log de MA- } \\
\text { DEI_2012 }\end{array}$} & $0.14449 \% * *$ & 0.0089 & 0.08521 & 0.00245 \\
\hline & $(0.05445)$ & & $(0.05582)$ & \\
\hline \multirow[t]{2}{*}{ Constante } & $-11.42934 * * *$ & & $-5.81145 \% *$ & \\
\hline & $(1.91679)$ & & $(2.01481)$ & \\
\hline $\mathrm{N}$ & 782 & & 782 & \\
\hline Pseudo R2 & 0,203 & & 0,164 & \\
\hline Log likelihood & $-225,60$ & & $-148,558$ & \\
\hline Wald chi2(9) & $102,01 * * *$ & & $56,74 * \cdots *$ & \\
\hline
\end{tabular}

Notas: Erros-padrão entre parênteses abaixo dos coeficientes. $* * *, *$ * $*$ Significante ao nível de $1 \%$, $5 \%$, e $10 \%$, respectivamente.

Nos dois modelos observou-se que o número de estabelecimentos operados por produtores na condição de parceiro, assentado ou ocupante e a área plantada de soja diminuem a probabilidade de o município ora ser participante do PMV ou ser classificado como consolidado ou monitorado e sob controle e participante do PMV, ainda que nem todos os coeficientes sejam significativos. A variável área do município apresentou efeito positivo sobre a probabilidade de participar do PMV quando se considera todos os 92 participantes, embora a reduza na consideração de apenas "consolidados" e "monitorados e sob controle", apesar de não ser estatisticamente significativa.

Foram utilizadas também como variáveis de controle a representação política em cada município. Atentando-se apenas ao sinal dos coeficientes obtidos e de seus efeitos marginais, pode concluir que municípios que são governados pelos partidos políticos PT, PMDB e PSB têm maior probabilidade de participar do programa relativamente a um grupo de outros partidos presentes no país, e excluídos 
da estimação, a saber, PC do B, PDT, PHS, PMN, PPS, PR, PRB, PRP, PRTB, PSC, PSDC, PSL, PTB, PTC, PTN e PV. Também se observa a redução da probabilidade de participar do programa para os dois grandes partidos de oposição ao governo federal nos últimos anos, a saber, PSDB e DEM, também em relação aos municípios governados por um dos partidos excluídos da estimação, agregados no grupo de "outros partidos", embora no caso do PSDB o efeito sobre a probabilidade de participar do programa seja positivo no cenário alternativo do trabalho

O próximo passo dentro da análise de impacto é calcular as probabilidades esperadas (propensity scores) dos dois modelos logits e proceder com análise de impacto através do pareamento usando os diferentes algoritmos. Como descrito na metodologia, os algoritmos escolhidos fazem usos dessas probabilidades esperadas para montar um grupo de controle (pareado) que possua as mesmas características do grupo tratado com exceção do emparelhamento covariado (covariate matching). Como enfatizado na metodologia, esta última técnica - de emparelhamento covariado (covariate matching) - também faz uso de distâncias euclidianas. No entanto, considera diretamente todas as variáveis no procedimento, com exceção do próprio escore de propensão.

Gráfico 3 - Distribuição de probabilidade de participar do PMV antes do emparelhamento.

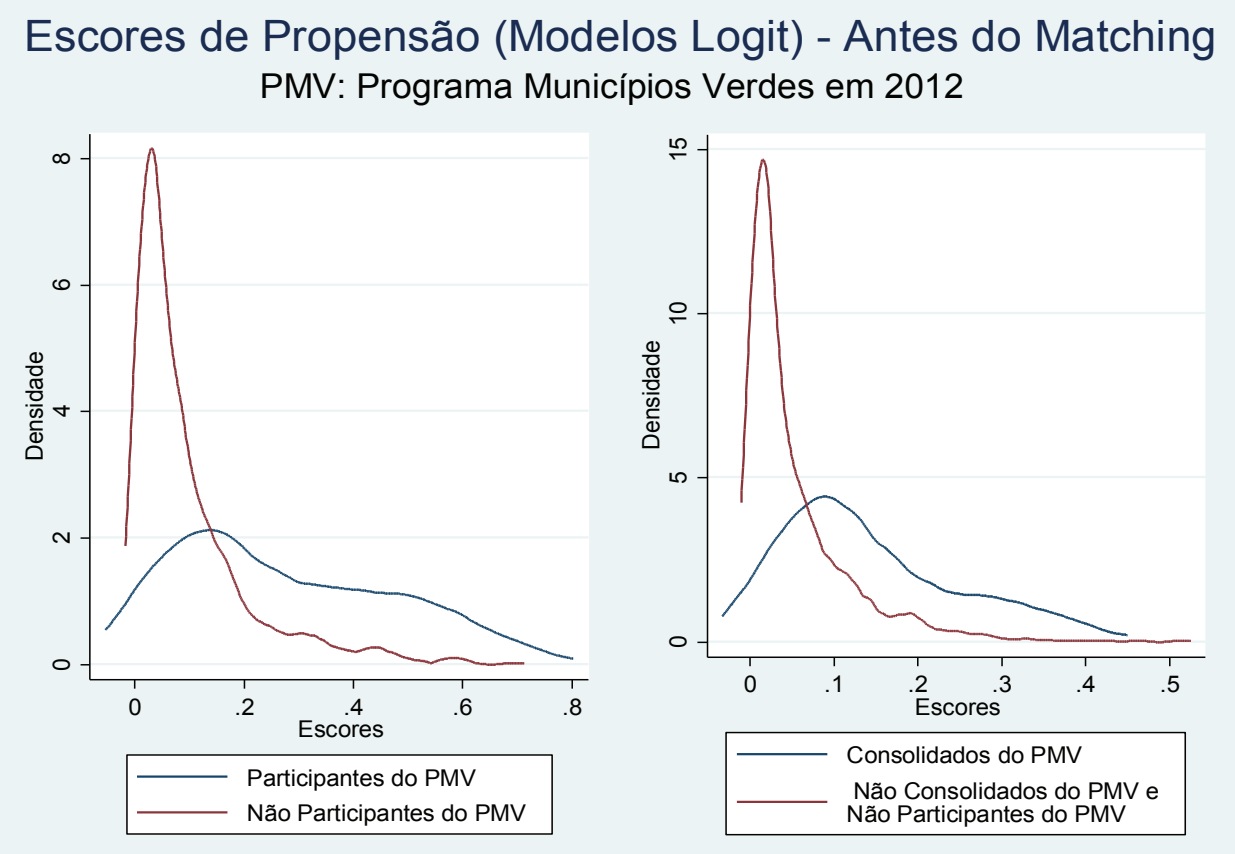

Fonte: Elaborado pelos autores utilizando o software STATA v13. 
O gráfico 3 apresenta as distribuições de probabilidade de participar do PMV nos dois cenários analisados neste trabalho para cada um dos grupos considerados participantes e não participantes antes do emparelhamento. O objetivo do emparelhamento é exatamente tornar as distribuições de probabilidade de participar as mais semelhantes possível entre tratamento e controle, o que corresponde, em outras palavras, a escolher entre os não participantes um grupo estatísticamente muito parecido com o dos participantes.

Leuven e Sianesi (2003) desenvolveram um procedimento para o software STATA que não somente realiza o cálculo do impacto de acordo com algoritmo escolhido (livre pelo usuário), mas também fornece os testes de balanceamento entre os grupos após o pareamento obtido em cada algoritmo. Como mencionado anteriormente na metodologia, diferenças estatisticamente significativas das características observáveis entre tratamento e controle não permitem pressupor que grupos de tratamento e de controle sejam similares (balanceados), o que poderia levar a estimativas tendenciosas do real impacto da intervenção. Assim, se existem diferenças estatísticas antes do emparelhamento, é esperado que essas desapareçam após o emparelhamento. $\mathrm{O}$ apêndice deste trabalho apresenta as estatísticas de balanceamento para todos os algoritmos considerados. Observou-se que praticamente todas as variáveis consideradas na obtenção dos escores de propensão para os algoritmos Vizinho Mais Próximo sem e com caliper, Kernel de Heckman e Local Linear, e também no emparelhamento covariado (covariate matching) foram balanceadas. Para a execução de todos os algoritmos propostos, visando evitar uma amostra mal pareada, a condição de suporte comum foi imposta (HEINRICH; MAFFIOLI; VÁSQUEZ, 2010).

Como dito anteriormente, constatando não haver diferenças estatísticas entre os grupos de tratamento e de controle, prossegue-se com a análise avaliando o impacto do programa. No presente estudo, foram utilizadas, como variáveis de interesse (outcomes), as variações das áreas desmatadas entre 2010 e 2011, 2011 e 2012, e 2012 e 2013. É importante lembrar que ao trabalhar com amostras pareadas e com a variável de interesse nas diferenças, está sendo aplicado o estimador diferenças nas diferenças (DD) para dados em painel, tendo a vantagem de isolar fatores não observáveis ou de difícil controle que estariam presentes entre os municípios nos quais se realizou o tratamento (RAVALLION, 2008).

Os resultados de avaliação de impacto do PMV na evolução do desmatamento para diversas técnicas de emparelhamento (sem reposição) estão apresentados na tabela 4. Como apresentado anteriormente, foram considerados municípios participantes do PMV versus não participantes, tendo como cenário alternativo, o impacto apenas para o grupo de municípios composto por "consolidados" e "monitorados e sob controle" que fizeram parte do PMV em 2012 versus os não "consolidados" e não "monitorados e sob controle" participantes do PMV e não participantes do programa em 2012.

No cenário base, ao utilizar o estimador DD sem a amostra pareada (esti- 
mador Nä̈ve) observa-se que entre os municípios participantes a variação (a mais) da área desmatada oscilou entre $14 \mathrm{~km}^{2}$ e $19 \mathrm{~km}^{2}$ ao ano no período analisado. Ou seja, claramente o crescimento do desmatamento é maior entre os municípios participantes do PMV. Contudo, ao comparar comparáveis, ou seja, amostra pareadas, a variação da área desmatada é consideravelmente menor - em torno de $6 \mathrm{~km}^{2}$ a 12 $\mathrm{km}^{2}$, a depender do algoritmo e ano selecionado -, ainda que nem todos os valores tenham apresentado níveis mínimos de significância. Com base nos resultados, fortalece-se a posição de que ingressar no PMV não possui efeito sobre o esforço local para diminuir o desmatamento, possivelmente devido a seu caráter de comprometimento voluntário na redução do mesmo, ou seja, não há enforcement.

Tabela 4 - Avaliação do Impacto do Programa Municípios Verdes sobre o desmatamento na Amazônia Legal

\begin{tabular}{|c|c|c|c|}
\hline \multirow[t]{2}{*}{ Técnicas de emparelhamento } & \multicolumn{3}{|c|}{$\begin{array}{l}\text { Estimador diferença nas diferenças } \\
\text { Resultado: Desmat }=\text { Desmat }_{\mathrm{t}}-\text { Desmat }_{\mathrm{t}-1} \\
\qquad\left(\mathrm{~km}^{2}\right)\end{array}$} \\
\hline & $\begin{array}{l}\text { Entre } 2010 \text { e } \\
\quad 2011\end{array}$ & $\begin{array}{l}\text { Entre } 2011 \text { e } \\
2012\end{array}$ & $\begin{array}{c}\text { Entre } 2012 \text { e } \\
2013\end{array}$ \\
\hline \multirow[t]{2}{*}{ Sem pareamento (Estimador Nä̈ve) } & $19.538 \% * \%$ & $14.0907 \div \div *$ & $17.001 * * *$ \\
\hline & $(2.364)$ & $(1.854)$ & $(2.572)$ \\
\hline \multicolumn{4}{|l|}{ Programas Municípios Verdes - PMV } \\
\hline \multirow[t]{2}{*}{ Vizinho Mais Próximo sem Caliper } & 10.747 & 5.953 & 6.026 \\
\hline & $(6.050) *$ & $(4.654)$ & $(6.659)$ \\
\hline \multirow[t]{2}{*}{$\begin{array}{l}\text { Vizinho Mais Próximo com Caliper } \\
\qquad(0,0338)^{\dagger}\end{array}$} & $11.248^{* *}$ & $6.476 *$ & 7.245 \\
\hline & $(4.836)$ & $(3.908)$ & $(5.294)$ \\
\hline \multirow[t]{2}{*}{ Kernel $(\text { bandwidth }=0,0218)^{\epsilon}$} & $10.614 * *$ & 6.196 & 6.679 \\
\hline & $(4.791)$ & $(3.903)$ & $(5.243)$ \\
\hline \multirow[t]{2}{*}{ Local Linear $(\text { bandwidth }=0,0218)^{\epsilon}$} & $11.088^{* *}$ & $6.708^{*}$ & 6.690 \\
\hline & $(4.835)$ & $(3.903)$ & $(5.291)$ \\
\hline \multirow[t]{2}{*}{ Emparelhamento (matching covariado) } & $12.220 *$ & 8.003 & 10.133 \\
\hline & $(6.648)$ & $(4.878)$ & $(6.999)$ \\
\hline
\end{tabular}


(continua)

\begin{tabular}{|c|c|c|c|}
\hline \multicolumn{4}{|c|}{$\begin{array}{c}\text { Programa Municípios Verdes (PMV) - Somente Consolidados e Monitorados e sob } \\
\text { controle }\end{array}$} \\
\hline \multirow[t]{2}{*}{ Sem pareamento (Estimador Naïve) } & -1.492 & -1.5768 & -1.9610 \\
\hline & $(3.3425)$ & $(2.604)$ & $(3.583)$ \\
\hline \multirow[t]{2}{*}{ Vizinho Mais Próximo sem Caliper } & -5.504 & -1.823 & -0.664 \\
\hline & $(4.668)$ & $(2.099)$ & $(2.345)$ \\
\hline \multirow[t]{2}{*}{$\begin{array}{l}\text { Vizinho Mais Próximo com Caliper } \\
\qquad(0,0173)^{\dagger}\end{array}$} & $-7.462 \% * \%$ & $-4.758 * * *$ & $-4.982 * * * *$ \\
\hline & $(2.138)$ & $(1.704)$ & $(2.230)$ \\
\hline \multirow[t]{2}{*}{ Kernel $(\text { bandwidth }=0,0119)^{\epsilon}$} & $-7.617 * * *$ & $-4.724 * * *$ & $-5.064 * *$ \\
\hline & $(2.070)$ & $(1.657)$ & $(2.155)$ \\
\hline \multirow[t]{2}{*}{ Local Linear $(\text { bandwidth }=0,0119)^{\epsilon}$} & $-7.864 * * *$ & $-4.803 * * *$ & $-5.240 * *$ \\
\hline & $(2.093)$ & $(2.342)$ & $(2.181)$ \\
\hline \multirow[t]{2}{*}{ Emparelhamento (matching covariado) } & -3.681 & -2.381 & -1.523 \\
\hline & $(4.438)$ & $(2.342)$ & (3.595) \\
\hline
\end{tabular}

Fonte: Elaborado pelos autores.

Notas: Erros-padrão entres parênteses. $* * *, * * *$ Significante ao nível de $1 \%, 5 \%$, e $10 \%$, respectivamente. ${ }^{\dagger O}$ tamanho do calibre (caliper) é definido como um $1 / 4$ do desvio padrão do escore de propensão (ROSENBAUM; RUBIN, 1983). ${ }^{\circledR}$ A largura ótima da janela (optimal bandwidth) é calculado de acordo com a regra de bolso de Silverman (1986).

No cenário alternativo, utilizou-se municípios "consolidados" e "monitorados e sob controle" participantes do PMV que, de acordo com sua classificação, possuem médio a baixo risco de desmatamento. Para estes, os resultados confirmaram a hipótese deste trabalho, isto é, durante o período analisado, o crescimento do desmatamento foi significativamente menor (entre $2 \mathrm{~km}^{2}$ e $8 \mathrm{~km}^{2}$ a menos) em relação àqueles que não participavam do programa ou que participavam, mas não possuíam o status de consolidados ou monitorados e sob controle. Os resultados dessa avaliação ficaram não somente bastante robustos estatisticamente, como as estimativas de impacto relativamente próximas quando os diferentes algoritmos de emparelhamento são comparados. Uma das conclusões aferidas, portanto, é que para receber as vantagens que a redução do desmatamento ocasionaria, munícipios com altas ta- 
Santos; Almeida; Lacerda; Silva; Brito - Os impactos do Programa Municípios ...

xas de desmatamento deveriam, em nosso entendimento, fazer a "lição de casa" e se esforçar para diminuir seu risco de desmatamento a níveis semelhantes ou menores do que os municípios já consolidados.

\section{Conclusão}

Este trabalho procurou avaliar quantitativamente o impacto do Programa Municípios Verdes (PMV) do governo estadual paraense aplicando o estimador diferença nas diferenças à metodologia de avaliação de tratamento médio sobre os tratados conjugada com a técnica de emparelhamento por escore de propensão (propensity score matching - PSM). Os resultados confirmam os efeitos positivos do programa, entretanto, apenas para municípios com médio a baixo risco de desmatamento. Ao considerar todos os participantes, os municípios envolvidos apresentaram, inclusive, crescimento do desmatamento superior àquele observado por seus pares não participantes. Esse resultado sugere que o programa é efetivo apenas para cidades com margem mais ampla para alterar seus indicadores ambientais. Cidades com elevado risco demandariam grandes esforços para desacelerar o crescimento do desmatamento, o que poderia ser economicamente inviável ou de elevado custo social, por exemplo. Outra explicação sugerida consiste, como discutido ao longo do artigo, no fato de os benefícios apontados pela organização do programa não decorrerem diretamente do fato de o município participar do mesmo, mas sim do alcance de metas estratégicas propostas pelo PMV. Assim, uma cidade não participante poderia igualmente ter os benefícios da maior segurança jurídica, ICMS Verde ou crédito facilitado desde que, isoladamente, adotasse políticas ambientais sugeridas pelo PMV sem, todavia, se comprometer formalmente com os objetivos, enquanto uma cidade participante poderia, por diversas razões, não conseguir ou não se engajar em atingir tais metas.

Os resultados reforçam, então, a necessidade do desenho de políticas específicas conforme o grau de risco em relação ao desmatamento, estratégia já abarcada pelo PMV. Evidentemente, mais tempo de análise seria necessário para avaliar o PMV adequadamente, abrindo oportunidades para estudos futuros dessa importante iniciativa pública. Ademais, a análise desenvolvida possui outras limitações, entre elas uma comumente associada a estudos onde as variáveis são levantadas em nível municipal, que consiste no efeito espacial - interação socioeconômica, politica, agrária, antropológica, etc. - que existe entre os agentes envolvidos (no caso nosso os municípios) e seus vizinhos. Além da correlação espacial, futuros estudos poderiam considerar também outros fatores como, por exemplo, aspectos climáticos, que poderiam determinar a participação de municípios em programas de redução do desmatamento, bem como outros problemas ambientais. 


\section{Referências}

ANDERSEN, L. E. et al. The Dynamics of Deforestation and Economic Growth in the Brazilian Amazon. Cambridge, UK: Cambridge University Press, 2002. Crossef http://dx.doi.org/10.1017/CBO9780511493454

ANGRIST, J. D.; PISCHKE, J. Mostly Harmless Econometrics. Princeton: Princeton University Press, 2009.

ARAUJO, C. et al. Property rights and deforestation in the Brazilian Amazon. Ecological Economics, Amsterdam, v. 69, n. 8-9, p. 2461-2468, 15 Jun. 2009. Crossef http://dx.doi.org/10.1016/j.ecolecon.2008.12.015

AUSTIN, P. C.; A Comparison of 12 Algorithms for Matching on the Propensity Score. Statistics in Medicine, New York, v. 33, n. 6, p. 1057-1069, 15 Mar. 2014. rossef http://dx.doi.org/10.1002/sim.6004

BARONA, E. et al. The role of pasture and soybean in deforestation of Brazilian Amazon. Environmental Research Letters, Bristol, UK, v. 5, n. 2, 16 Apr. 2010. rossef http://dx.doi.org/10.1088/1748-9326/5/2/024002

BRANDÃO, A, S, P.; REZENDE, G. C.; MARQUES, R., W. C. Agricultural growth in the Period 1999-2004, outburst in soybeans areas and environmental impacts in Brazil. Rio de Janeiro: IPEA, 2005. (Texto para discussão n. 1062).

BRAVO-URETA, B. Stochastic Frontiers, Producitvity Effects and Development Projects. Economics and Business Letters, Oviedo, v. 3, n. 1, p. 51-58, 2014. Grosses http://dx.doi.org/10.17811/ebl.3.1.2014.51-58

BRASIL. Banco Central do Brasil. Resolução n. 4138, de 27 de setembro de 2012. Dispõe sobre ajustes nas condições básicas do Crédito Rural. Disponível em: <http://www.bcb.gov.br>. Acesso em: 21 mar. 2015.

BECKER, S. O.; ICHINO, A. Estimation of average treatment effects based on propensity scores. The Stata Journal, College Station, v. 2, n. 4, p. 358-377, 2002.

CALIENDO, M.; KOPEINIG, S. Some practical guidance for the implementation of propensity score matching. Journal of Economic Surveys, Oxford, v. 22, n. 1, p. 31-72, 31 Jan. 2008. Crossef http://dx.doi.org/10.1111/j.1467-6419.2007.00527.x

CAMERON, A.; TRIVEDI, P. Microeconometrics: Methods and Applications. Cambridge, UK: Cambridge University Press, 2005. Crossef http://dx.doi. org/10.1017/CBO9780511811241 

Santos; Almeida; Lacerda; Silva; Brito - Os impactos do Programa Municípios ...

CERDÁN-INFANTES, P.; MAFFIOLI, A.; UBFAL, D. The impact of agricultural extension services: the case of grape production in Argentina. Washington, DC: IADB, 2008. (OVE Working Paper n. 508).

CHOMITZ, K. M.; THOMAS, T. S. Determinants of land use in Amazonia: a fine-scale spatial analysis. American Journal of Agricultural Economics, Urbana, v. 85, n. 4, p. 1016-1028, Nov. 2003. Erossef http://dx.doi.org/10.1111/1467-8276.00504

D'AGOSTINO, R. B. Tutorial in Biostatistics: Propensity Score Methods for Bias Reduction in the Comparison of a Treatment to a Non-Randomized Control Group. Statistics in Medicine, New York, v. 17, p. 2265-2281, 15 Oct. 1998. Crossef http://dx.doi. org/10.1002/(SICI)1097-0258(19981015)17:19<2265::AID-SIM918>3.0.CO;2-B

DINIZ, M. B. et al. Causas do desmatamento da Amazônia: uma aplicação do teste de causalidade de Granger acerca das principais fontes de desmatamento nos municípios da Amazônia Legal brasileira. Nova Economia, Belo Horizonte, v. 19, n. 1, p. 121-159, Jan./Abr. 2009. Crossef http://dx.doi.org/10.1590/S0103-63512009000100006

DUFLO, E.; GLENNERSTER, R.; KREMER, M. Using randomization in development economics research: A Toolkit. In: T. SCHULTZ; J. STRAUSS (Ed.). Handbook of Development Economics. Amsterdam: Elsevier, 2008. p. 3895-3962.

FARIA, W. R.; ALMEIDA, A. N. Relationship between openness to trade and deforestation: empirical evidence from the Brazilian Amazon. Ecological Economics, Amsterdam, v. 121, p. 85-97, Jan. 2016. Crosses http://dx.doi.org/10.1016/j.ecolecon.2015.11.014

FEARNSIDE, P. M. Desmatamento na Amazônia: dinâmica, impactos e controle. Acta Amazonica, Manaus, v. 36, n. 3, 2006. p. 395-400. Grossef http://dx.doi. org/10.1590/s0044-59672006000300018

GERTLER, P. J. et al. Impact Evaluation in Practice. Washington, DC: The World Bank Group, 2011.

HECKMAN, J. et al. Matching as an Econometric Evaluation Estimator: Evidence from Evaluating a Job Training Programme. Review of Economic Studies, London, v. 64, n. 4, p. 605-654, Oct. 1997. Crossef http://dx.doi.org/10.2307/2971733

HEINRICH, C.; MAFFIOLI, A.; VÁSQUEZ, G. A Primer for Applying Propensity-Score Matching. Washington, DC: Inter-American Development Bank, 2010. (Technical Note, n. 161).

IMBENS, G. M.; WOOLDRIDGE, J. M. Recent developments in the econometrics of program evaluation. Cambridge: NBER, 2008. (Working Paper n. 14251). 
INSTITUTO BRASILEIRO DE GEOGRAGIA E ESTATÍSTICA. Sistema IBGE de Recuperação Automática. Disponível em: <http://www.sidra.ibge.gov.br/>. Acesso em: 15 mar. 2015.

INSTITUTO NACIONAL DE PESQUISAS ESPACIAIS. Projeto de Estimativa do Desflorestamento da Amazônia. Disponível em: < http://www.obt.inpe.br/prodes/index.php>. Acesso em: 15 mar. 2015.

KAIMOWITZ, D. et al. A Conexão Hambúrguer Alimenta a Destruição da Amazônia: desmatamento e pecuária na Amazônia. Jakarta: Center for International Forestry Research, 2004. 11 p. Nota técnica.

KHANDKER, S. R.; KOOLWAL, G. B.; SAMAD, H. A. Handbook on Impact Evaluation: Quantitative Method and Practices. Washington, DC: World Bank, 2009. rossef http://dx.doi.org/10.1596/978-0-8213-8028-4

LEUVEN, E.; SIANESI, B. PSMATCH2: STATA module to perform full Mahalanobis and propensity score matching, common support graphing, and covariate imbalance testing. Boston: Boston College, Department of Economics, 2003. Disponível em: <http://econpapers.repec.org/software/bocbocode/s432001.htm>. Acesso em 20 mar. 2015.

MAFFIOLI, A. et al. Improving Technology Adoption in Agriculture through Extension Services: Evidence from Uruguay. Journal of Development Effectiveness, Abingdon, v. 5, n. 1, p. 64-81, 15 Feb. 2013. Crossef http://dx.doi.org/10.1080/194 39342.2013.764917

MARGULIS, S. Causes of Deforestation of the Brazilian Amazon. Washington, DC: World Bank, 2004. (Working Paper n. 22).

MERTENS, B. et al. Crossing spatial analyses and livestock economics to understand deforestation processes in the Brazilian Amazon: the case of São Félix do Xingú in South Pará. Agricultural Economics, Haboken, v. 27, n. 3, p. 269-294, Nov. 2002.

PEREIRA, D. et al. ICMS Verde. Belém: Governo do Estado do Pará, 2014. 6 p. Nota técnica.

PFAFF, A. S. What drives deforestation in the Brazilian Amazon? Journal of Environmental Economics and Management, New York, v. 37, n. 1, p. 26-43, Jan. 1999. rossef http://dx.doi.org/10.1006/jeem.1998.1056

PFAFF, A. S. et al. Road investments, spatial intensification and deforestation in the Brazilian Amazon, Journal of Regional Sciences, Malden, v. 47, n. 1, p. 109-123, Feb. 2007. Crossef http://dx.doi.org/10.1111/j.1467-9787.2007.00502.x 
PRATES, R. C.; SILVA, C.B. Desflorestamento Amazônia Legal. In: CONGRESSO DA SOCIEDADE BRASILEIRA DE ECONOMIA, ADMINISTRAÇÃO E SOCIOLOGIA RURAL, 45., 2007, Londrina, Anais Eletrônicos... Londrina: SOBER, 2007. Disponível em: <http://www.sober.org.br/palestra/6/282.pdf>. Acesso em: 21 mar. 2015.

RAVALLION, M. Evaluating anti-poverty program. In: T. SCHULTZ; J. STRAUSS (Ed.). Handbook of Development Economics. Amsterdam: Elsevier, 2008. p. 3787-3846.

REIS, E. J.; GUZMAN, R. M. An Econometric Model of Amazon Deforestation. Rio de Janeiro: IPEA, 1992. (Texto para Discussão n. 265). RIVERO et al. Pecuária e desmatamento: uma análise das principais causas diretas do desmatamento na Amazônia. Nova Economia, Belo Horizonte, v. 19, n. 1, p. 41-66, Jan./Abr. 2009. rossef http://dx.doi.org/10.1590/S0103-63512009000100003

RIVERO et al. Pecuária e desmatamento: uma análise das principais causas diretas do desmatamento na Amazônia. Nova Economia, Belo Horizonte, v. 19, n. 1, p. 4166, Jan./Abr. 2009.

ROSENBAUM, P.; RUBIN, D. The central role of the propensity score in observational Studies for Causal Effects. Biometrika, Oxford, v. 70 n. 1, p. 41-55. 1983. erossef http://dx.doi.org/10.1093/biomet/70.1.41

SILVA, D. S; BARRETO, P. O aumento da produtividade e lucratividade da pecuária bovina na Amazônia: o caso do Projeto Pecuária Verde em Paragominas. Belém: Imazon, 2014.

SILVERMAN, B. W. Density estimation for statistics and data analysis. London: Chapman and Hall, 1986. erossef http://dx.doi.org/10.1007/978-1-4899-3324-9

SMITH, H. L. Matching with Multiple Controls to Estimate Treatment Effects in Observational Studies. Sociological Methodology, San Francisco, v. 27, n. 1, p. 325353, 1997. Crossef http://dx.doi.org/10.1111/1467-9531.271030

SOARES-FILHO, B. S.; NESPTAD, D. C.; CURRAN, L. Cenários de desmatamento para a Amazônia. Estudos Avançados, São Paulo, v. 45, n. 15, p. 31-36, Mai./Aug. 2005.

THE NATURE CONSERVANCY. ICMS Ecológico. Disponível em: <http:// www.icmsecologico.org.br/>. Acesso em: 25 mai. 2016.

WALKER, R.; MORAN, E.; ANSELIN, L. Deforestation and cattle ranching in the Brazilian Amazon: external capital and household processes. World Development, Washington, DC, v. 28, n. 4, p. 683-699, Apr. 2000. Crossef http://dx.doi. org/10.1016/s0305-750x(99)00149-7 
WEINHOLD, D.; REIS, E. Model evaluation and causality testing in short panels: the case of infrastructure provision and population growth in the Brazilian Amazon. Journal of Regional Science, Philadelphia, v. 41, n. 4, p. 639-658, Jan. 2001. crossef http://dx.doi.org/10.1111/0022-4146.00236

WEINHOLD, D; REIS, E. Land Use and Transportation Costs in the Brazilian Amazon. Madison: Department of Agricultural \& Applied Economics of University of Wisconsin-Madison, 2004. (Staff Paper n. 467).

WHATELY, M.; CAMPANILI, M. (Coord.). Programa Municípios Verdes: Lições aprendidas e desafios para 2013/2014. Belém: Governo do Estado, Programa Municípios Verdes, 2013.

VIANA, V. et al. Impactos do Programa Bolsa Floresta: uma avaliação preliminar. Inclusão Social, Brasília, v. 6, n. 1, p. 201-218, Jul./Dez. 2012.

\section{Apêndice}

APENNDICE A - Estatísticas de balanceamento entre participantes do PMV e não participantes.

\begin{tabular}{|c|c|c|c|c|c|c|c|c|c|c|}
\hline & \multicolumn{2}{|c|}{$\begin{array}{l}\text { Vizinho mais } \\
\text { próximo sem } \\
\text { caliper }\end{array}$} & \multicolumn{2}{|c|}{$\begin{array}{c}\text { Vizinho mais } \\
\text { próximo com } \\
\text { caliper }\end{array}$} & \multicolumn{2}{|c|}{ Kernel } & \multicolumn{2}{|c|}{ Local Linear } & \multicolumn{2}{|c|}{$\begin{array}{l}\text { Covariate } \\
\text { matching }\end{array}$} \\
\hline & $\begin{array}{l}\text { Viés } \\
\text { em \% }\end{array}$ & $\mathrm{p}$-value & $\begin{array}{l}\text { Viés } \\
\text { em \% }\end{array}$ & $\mathrm{p}$-value & $\begin{array}{l}\text { Viés } \\
\text { em \% }\end{array}$ & $\mathrm{p}$-value & $\begin{array}{c}\text { Viés } \\
\text { em \% }\end{array}$ & p-value & $\begin{array}{c}\text { Viés } \\
\text { em \% }\end{array}$ & $\begin{array}{c}\text { p-va- } \\
\text { lue }\end{array}$ \\
\hline $\operatorname{lnareakm} 2$ & $-9,9$ & 0,49 & 1 & 0,95 & 1,7 & 0,91 & 0,2 & 0,99 & 27,4 & 0,05 \\
\hline lnpop & 11,4 & 0,42 & 0,9 & 0,95 & 1,1 & 0,94 & 1,6 & 0,91 & 4,4 & 0,72 \\
\hline lnboi & 16,3 & 0,31 & $-0,9$ & 0,95 & $-0,3$ & 0,98 & $-2,2$ & 0,87 & 5,3 & 0,69 \\
\hline Insoja12 & $-10,5$ & 0,45 & 1,8 & 0,89 & 1,1 & 0,94 & 1,9 & 0,88 & $-0,4$ & 0,98 \\
\hline lnpropriet & 2,2 & 0,87 & 7,3 & 0,6 & 7,2 & 0,61 & 5,5 & 0,69 & 20,4 & 0,14 \\
\hline lnassenta & 13,1 & 0,39 & 2,6 & 0,86 & 3,1 & 0,84 & 2 & 0,89 & 2 & 0,88 \\
\hline Inparceiro & $-2,2$ & 0,88 & 1,4 & 0,92 & 0,9 & 0,95 & $-0,4$ & 0,98 & 0,2 & 0,99 \\
\hline Inocupante & 0,8 & 0,95 & 4,2 & 0,77 & 4,8 & 0,74 & 3,9 & 0,78 & 5,5 & 0,69 \\
\hline pt2008 & 6,1 & 0,71 & $-4,4$ & 0,8 & $-6,7$ & 0,69 & $-13,9$ & 0,42 & 0 & 1 \\
\hline psdb2008 & -4 & 0,79 & $-2,3$ & 0,88 & -4 & 0,79 & $-0,7$ & 0,96 & 0 & 1 \\
\hline $\operatorname{dem} 2008$ & 0 & 1 & $-1,4$ & 0,91 & -2 & 0,87 & $-1,7$ & 0,89 & 0 & 1 \\
\hline pmdb2008 & $-2,7$ & 0,86 & 6,6 & 0,67 & 7,2 & 0,64 & 9,1 & 0,55 & 0 & 1 \\
\hline pp2008 & 10,5 & 0,16 & $-2,1$ & 0,85 & $-2,1$ & 0,85 & $-1,5$ & 0,89 & 0 & 1 \\
\hline psb2008 & $-5,8$ & 0,73 & 1,9 & 0,91 & 1,9 & 0,9 & 2,4 & 0,88 & 0 & 1 \\
\hline $\operatorname{lnwood} 2012$ & $-0,1$ & 1 & 1,1 & 0,93 & 2,8 & 0,82 & 3,7 & 0,76 & 7,8 & 0,53 \\
\hline
\end{tabular}


APÊNDICE B - Estatísticas de balanceamento entre participantes do PMV (somente consolidados e monitorados e sob controle) e não participantes.

\begin{tabular}{|c|c|c|c|c|c|c|c|c|c|c|}
\hline & \multicolumn{2}{|c|}{$\begin{array}{l}\text { Vizinho mais } \\
\text { próximo sem } \\
\text { caliper }\end{array}$} & \multicolumn{2}{|c|}{$\begin{array}{l}\text { Vizinho mais } \\
\text { próximo com } \\
\text { caliper }\end{array}$} & \multicolumn{2}{|c|}{ Kernel } & \multicolumn{2}{|c|}{ Local Linear } & \multicolumn{2}{|c|}{$\begin{array}{l}\text { Covariate } \\
\text { matching }\end{array}$} \\
\hline & $\begin{array}{r}\text { Viés } \\
\text { em \% }\end{array}$ & $\mathrm{p}$-value & $\begin{array}{c}\text { Viés } \\
\text { em \% }\end{array}$ & p-value & $\begin{array}{l}\text { Viés } \\
\text { em \% }\end{array}$ & $\mathrm{p}$-value & $\begin{array}{c}\text { Viés } \\
\text { em \% }\end{array}$ & $\mathrm{p}$-value & $\begin{array}{l}\text { Viés } \\
\text { em \% }\end{array}$ & $\begin{array}{c}\text { p-va- } \\
\text { lue }\end{array}$ \\
\hline lnareakm2 & $-9,7$ & 0,62 & $-32,8$ & 0,09 & $-33,5$ & 0,09 & $-33,4$ & 0,09 & $-48,8$ & 0,01 \\
\hline $\operatorname{lnpop}$ & 8,1 & 0,66 & $-0,1$ & 1 & 0,6 & 0,98 & 2,4 & 0,9 & 1,5 & 0,92 \\
\hline lnboi & 13 & 0,58 & 6,9 & 0,74 & 5,2 & 0,8 & 4,8 & 0,81 & 3 & 0,88 \\
\hline lnsoja12 & $-38,8$ & 0,03 & $-49,5$ & 0,01 & -50 & 0,01 & $-48,9$ & 0,01 & $-49,1$ & 0,01 \\
\hline Inpropriet & 16,9 & 0,35 & -1 & 0,95 & 0 & 1 & $-0,1$ & 1 & 15,2 & 0,38 \\
\hline lnassenta & 42,3 & 0,05 & $-0,4$ & 0,99 & $-1,6$ & 0,94 & $-1,4$ & 0,95 & $-8,2$ & 0,69 \\
\hline Inparceiro & 16 & 0,25 & 2 & 0,9 & 2,1 & 0,9 & 2,9 & 0,86 & 6 & 0,7 \\
\hline Inocupante & 20,6 & 0,28 & 13,4 & 0,49 & 14,1 & 0,47 & 15,2 & 0,44 & 11,6 & 0,55 \\
\hline pt2008 & 28,3 & 0,24 & 12,9 & 0,6 & 11,4 & 0,65 & 11,1 & 0,66 & $-2,8$ & 0,91 \\
\hline psdb2008 & $-42,3$ & 0,09 & -34 & 0,15 & $-32,1$ & 0,16 & $-31,1$ & 0,18 & -34 & 0,13 \\
\hline $\operatorname{dem} 2008$ & $-6,2$ & 0,67 & 1 & 0,94 & 0,9 & 0,94 & 1,4 & 0,91 & $-0,4$ & 0,98 \\
\hline pmdb2008 & $-13,7$ & 0,54 & 11,4 & 0,59 & 12,1 & 0,57 & 12,2 & 0,57 & 22,6 & 0,28 \\
\hline pp2008 & $-4,9$ & 0,79 & 2,1 & 0,9 & 2,4 & 0,89 & 2,1 & 0,9 & $-0,7$ & 0,97 \\
\hline psb2008 & 16,5 & 0,52 & $-0,9$ & 0,97 & $-1,8$ & 0,95 & $-4,1$ & 0,89 & $-1,5$ & 0,96 \\
\hline $\operatorname{lnwood} 2012$ & $-16,7$ & 0,38 & $-20,5$ & 0,32 & $-20,5$ & 0,31 & $-20,3$ & 0,32 & $-27,3$ & 0,17 \\
\hline
\end{tabular}

Recebido em 20.04.15

Aprovado em 17.06.16 